\title{
Catheter-related septic thrombophlebitis of the great central veins successfully treated with low-dose streptokinase thrombolysis and antimicrobials
}

\author{
Patricia Volkow*†1, Patricia Cornejo-Juárez ${ }^{\dagger 1}$, Ana Berta Arizpe-Bravo ${ }^{1}$, \\ Jorge García-Méndez¹, Enrique Baltazares-Lipp² and Rogelio Pérez-Padilla ${ }^{\dagger 2}$
}

Address: ${ }^{1}$ Mexican National Institute of Cancer (INCan), Mexico City, Mexico and ${ }^{2}$ Mexican National Institute of Respiratory Diseases (INER), Mexico City, Mexico

Email: Patricia Volkow* - volkow@perezpadilla-volkow.com.mx; Patricia Cornejo-Juárez - patcornejo@yahoo.com; Ana Berta ArizpeBravo - anaarizpe@hotmail.com; Jorge García-Méndez - jorge021371@yahoo.com; Enrique Baltazares-Lipp - hildarocrespo@hotmail.com; Rogelio Pérez-Padilla - perezpad@servidor.unam.mx

* Corresponding author †Equal contributors

Published: 22 August 2005

Thrombosis Journal 2005, 3:11 doi:10.1186/1477-9560-3-1I
Received: 31 May 2005

Accepted: 22 August 2005

This article is available from: http://www.thrombosisjournal.com/content/3/I/II

(c) 2005 Volkow et al; licensee BioMed Central Ltd.

This is an Open Access article distributed under the terms of the Creative Commons Attribution License (http://creativecommons.org/licenses/by/2.0), which permits unrestricted use, distribution, and reproduction in any medium, provided the original work is properly cited.

\begin{abstract}
Background: Septic thrombophlebitis is an iatrogenic life-threatening disease associated with use of central venous devices and intravenous (IV) therapy. In cancer patients receiving chemotherapy, vein resection or surgical thrombectomy in large central venous lines is time-consuming, can delay administration of chemotherapy, and therefore can compromise tumor control. Experience with thrombolysis has been published for catheter-related thrombosis but for septic thrombosis, this experience is scarce.

Results: We describe three patients with cancer and septic thrombophlebitis of central veins caused by Staphylococcus aureus treated with catheter removal, thrombolysis, and intravenous (IV) antibiotics. In our reported cases, an initial bolus of 250,000 international units (IU) of streptokinase administered during the first $\mathrm{h}$ followed by an infusion of $20,000-40,000 \mathrm{IU} / \mathrm{h}$ for $24-36 \mathrm{~h}$ through a proximal peripheral vein was sufficient to dissolve the thrombus. After thrombolyisis and parenteral antibiotic for 4-6 weeks the septic thrombosis due to Staphylococcus aureus solved in all cases. No surgical procedure was needed, and potential placement of a catheter in the same vein was permitted.
\end{abstract}

Conclusion: Thrombolysis with streptokinase solved symptoms, cured infection, prevented embolus, and in all cases achieved complete thrombus lysis, avoiding permanent central-vein occlusion.

\section{Background}

Septic thrombophlebitis is an iatrogenic life-threatening disease associated with use of central venous devices and intravenous (IV) therapy. [1-3] Sole use of antimicrobials is rarely effective for controlling infection, requiring removal of the device and anticoagulation but in some cases a more aggressive approach such as resection of the affected vein [2,4-7] or trombectomy is needed [8]. Vein resection or surgical thrombectomy is time-consuming in large central venous lines, has a high rate of 


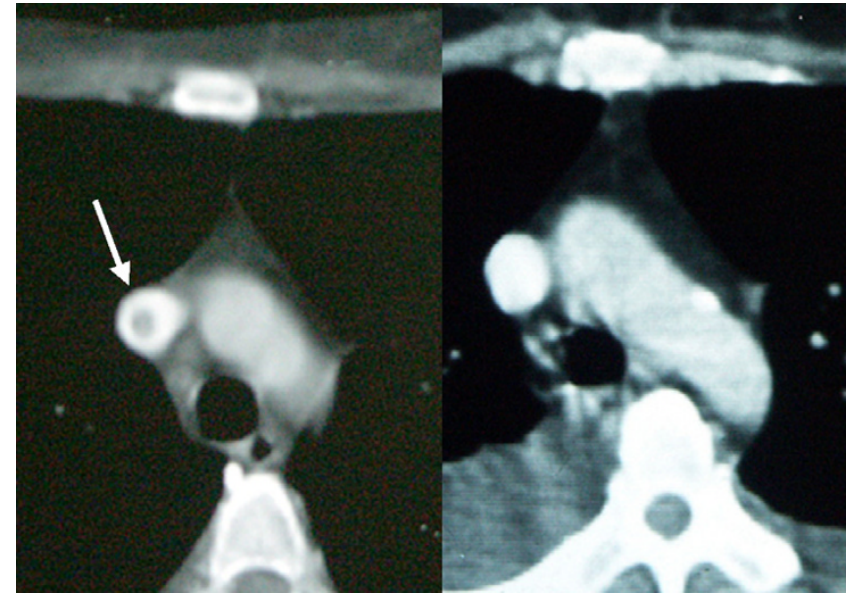

Figure I

CT scan showing thrombus before and after thrombolysis. Ia. CT scan of superior vena cava with intravenous contrast infusion showing a thrombus before streptokinase infusion. Ib. CT scan of superior vena cava with intravenous contrast infusion three days after thrombolysis showing no remaining thrombus.

complications, can delay administration of chemotherapy, and therefore delay or impede tumor control. Experience with thrombolysis has been published for catheterrelated thrombosis [9-13] but for septic thrombosis, this experience is scarce. $[14,15]$ Herein, we describe three women with cancer and septic thrombophlebitis due to Staphylococcus aureus methicillin sensitive, who failed to resolve with catheter removal, parenteral antibiotics, and anticoagulation therapy and who were successfully treated with low-dose streptokinase fibrinolysis. All patients were receiving chemotherapy through non-tunneled polyurethane, single-lumen catheters placed in the subclavian-vein, but none of them had coagulopathy or septic shock.

\section{Results \\ Case I}

This was the case of a woman 59-years-of-age with papillary ovarian adenocarcinoma. She had been treated during the previous 10 years with $10 \mathrm{mg} /$ day of prednisone for rheumatoid arthritis. A first central-vein catheter was placed for adjuvant chemotherapy and removed 4 months later with no complications. A new catheter was set in place 8 months later after documenting tumor relapse; however, one day later the patient developed pain at the insertion site and fever $\left(39^{\circ} \mathrm{C}\right)$, and chills. An abscess at insertion site was found and the catheter was removed. Blood cultures, purulent secretion, and catheter tip were positive for Staphylococcus aureus. Intravenous dicloxacil- lin was initiated and amikacin was added 1 day later, but fever and positive blood cultures persisted. Echo-Doppler documented thrombosis of brachiocephalic trunk and computed tomography (CT) scan showed a thrombus reaching brachiocephalic trunk and superior vena cava (Figure 1a); subcutaneous (SC) enoxaparin was initiated. Vancomycin was started because fever and bacteremia persisted, with no clinical improvement. Seven days after beginning with antibiotics, the patient received an initial bolus of 250,000 international units (IU) of streptokinase administered in $1 \mathrm{~h}$ followed by an infusion of 40,000 IU per $\mathrm{h}$ for $24 \mathrm{~h}$ through a peripheral vein. One day after thrombolysis began, fever and positive blood cultures disappeared. Full permeability of right brachiocephalic vein and superior vena cava was documented by CT scan (Figure $1 \mathrm{~b}$ ). The patient completed 4 weeks of parenteral antibiotics, but died 1 month later with peritoneal carcinomatosis-related intestinal occlusion. Necropsy study showed neither thrombosis nor obstruction of great central veins.

\section{Case 2}

A 42-year-old woman with breast cancer stage IIIB was started on chemotherapy. Four months later, she was admitted with fever, shivering, and painful erythematous lesions disseminated in legs and arms. The patient was initiated on IV vancomycin and amikacin, and after initial blood cultures grew oxacillin-sensitive $S$. aureus. The catheter was removed and antibiotics were changed to dicloxacillin and amikacin. Initial echo-Doppler for all limbs did not demonstrate obstruction to blood flow. Chest roentgenogram showed bilateral, multiple, rounded, irregular, non-cavitated opacities. Transthoracic echocardiography did not show heart valve vegetations, but did show a mobile hyper-reflectant image in superior vena cava extending to right atrium, suggestive of thrombus. Fever persisted and new painful nodular erythemathous lesions appeared in both limbs that evolved into abscesses, but neither purulent skin lesions nor blood cultures grew microorganisms. A second transthoracic echocardiogram performed 9 days later showed persistence of the same pediculated lesion that measured $40 \times 10$ $\times 10 \mathrm{~mm}$. The patient was thrombolyzed with the same doses of streptotokinase; $24 \mathrm{~h}$ later, she had no fever, all symptoms resolved and transthoracic echocardiography performed 9 days later showed no lesions. She completed 6 weeks with IV antimicrobials. A month later, the scheduled mastectomy was performed the patient received 11 courses of weekly paclitaxel. Ten months later, the patient is asymptomatic with no evidence of tumor activity.

\section{Case 3}

A 57-year-old woman with ovarian adenocarcinoma stage IV metastatic to lungs with a catheter placed in the right subclavian vein, through which she received four cycles of 
Table I: Demographic and clinical characteristics of the patients described

\begin{tabular}{|c|c|c|c|}
\hline Case & I & 2 & 3 \\
\hline Gender & $\mathrm{F}$ & $\mathrm{F}$ & $\mathrm{F}$ \\
\hline Age & 59 & 42 & 57 \\
\hline Cancer site & Ovarian (relapse) & Breast stage III-B & Ovarian stage IV \\
\hline $\begin{array}{l}\text { Time of catheter stay (days) before } \\
\text { symptoms }\end{array}$ & I & 155 & 63 \\
\hline Thrombus site & Superior vena cava & $\begin{array}{l}\text { Superior vena cava extended to } \\
\text { right atrium }\end{array}$ & Subclavian and yugular veins \\
\hline $\begin{array}{l}\text { Days of antimicrobials before } \\
\text { thrombolysis }\end{array}$ & 7 & 19 & 6 \\
\hline Indication for thrombolyis & Persitent fever and bacteremia. & $\begin{array}{l}\text { Persistent fever and septic } \\
\text { embolization }\end{array}$ & $\begin{array}{l}\text { Persitent fever and septic } \\
\text { embolization }\end{array}$ \\
\hline $\begin{array}{l}\text { Staphylococcus aureus methicillin } \\
\text { sensible }\end{array}$ & + & + & + \\
\hline Streptokinase dose & $\begin{array}{l}250,000 \mathrm{IU} \text { hr. bolus }+40,000 \text { us/ } \\
\text { hr for } 24 \mathrm{hrs} \text {. }\end{array}$ & $250,000 \mathrm{IU}$ us/hr bolus. & $\begin{array}{l}250,000 \text { us I hr. bolus }+25,000 \text { us/ } \\
\text { hr for } 12 \text { hrs. }\end{array}$ \\
\hline Thrombus lysis & $100 \%$ & $100 \%$ & $100 \%$ \\
\hline ARDS* & No & No & No \\
\hline
\end{tabular}

* Acute respiratory distress syndrome

carboplatin and paclitaxel. One week after the last chemotherapy cycle, she developed fever and pain in the right shoulder and two days later presented to the emergency room. At admission, the patient had persistent shoulder pain, anorexia, and an enlarging, painful mass in right shoulder, with an indurated, extremely tender area in right sternoclavicular joint and edema in right arm. She was febrile, hypotensive, and tachycardic. Oxacillin-sensitive Staphylococcus aureus grew in blood and catheter tip, and was started on dicloxacillin and amikacin. Echo-Doppler revealed a $4-\mathrm{cm}$ long thrombus within the right subclavian vein partially occluding the right jugular vein. No intracardiac thrombus or valvular lesions were observed in the Echocardiogram. CT scan showed a large collection of liquid in right shoulder sternoclavicular joint. The patient received an initial streptokinase bolus of 250,000 IU and one $12-\mathrm{h}$ infusion of $20,000 \mathrm{U} / \mathrm{h}$, followed by enoxaparin $60 \mathrm{mg}$ BID. Twenty four hours later, EchoDoppler showed patent right subclavian and jugular veins. She completed 3 weeks of enoxaparin and then changed to oral anticoagulation. Technetium bone scan showed evidence of ipsilateral clavicle osteomyelitis. She received IV antibiotics for 4 weeks followed by oral dicloxacillin plus rifampin for 28 weeks. After treatment the bone scan did not have evidence of osteomyelitis and 8 months later the patient had normal shoulder function without arm edema.

\section{Discussion}

Intravascular infection and thrombosis are two of the most serious complications related to central venous catheter use. Central vein thrombosis was described as a complication of catheters in 1971 [2]. Symptoms were present in $<4 \%$ of patients with central venous catheter when venography showed thrombosis [2]. Neoplastic disease often creates a thrombogenic state, through inflammation mediators, tumor necrosis factor, platelet activation, as well as a procoagulant substances released by tumor cells [15]. In addition, long indwelling lines increase risk for thrombosis, reported in $0.06-32 \%$ of patients, although the risk changes with type of catheter, neoplasia, chemotherapy regimes and radiation [16]. The complications of catheter-related thrombosis are similar although not as frequently as has been described for lower limb thrombosis [16]. It can produce pulmonary embolism. The trombus can become infected with persistent bacteremia and septic embolization ensue [17]. It has been recognized that CVC infection increases the risk of thrombosis [18] even though we believe that the incidence of septic thrombosis with persistent refractory bacteremia as the cases herein described is uncommon, in a recent review CVC associated thrombosis this complication is not mentioned [17]. For the last 6 years at a hospital where we placed $>1,100$ long indwelling catheters for cancer patients annually we have observed approximately one case every two years.

Standard therapy for catheter associated septic thrombosis includes antibiotics, catheter removal, full heparin anticoagulation, and venotomy. The latter is technically impossible for great central veins, although surgical thrombectomy has been successfully performed [8] and medical lysis of the thrombus is feasible $[13,14]$. We describe successful lysis of septic thrombosis with lowdose streptokinase infusion through a peripheral vein proximal to central great vein affected and no surgical or invasive procedure performed. This approach was first reported with a high percentage of success in catheter- 
related thrombosis in the early 1980 s, allowing to maintain vein patency $[4,6]$ using streptokinase, urokinase, and more recently, recombinant-tissue plasminogen activator, $[13,14]$. In our reported cases, streptokinase administered as initial bolus of 250,000 IU during 1 hour followed by infusion of 20,000-40,000 IU/h for 24-36 hours through a proximal peripheral vein was sufficient to dissolve the thrombus Table 1 . This treatment solved symptoms, cured infection, prevented embolus, and in all cases achieved complete thrombus lysis, avoiding permanent centralvein occlusion. The episode of septic thrombosis due to Staphylococcus aureus solved with continued parenteral antibiotic for 4 to 6 weeks in all cases and no surgical procedure was required.

\section{Conclusion}

Fibrinolytic therapy with streptokinase is a therapeutic option in the management of catheter-related septic thrombophlebitis of the great central veins. This therapeutic approach, mantain central vein patency, allowing potential to place a new long indwelling catheter, the cornerstone for cancer patients who need chemotherapy.

\section{List of abbreviations}

IV - intravenous

IU - International units

CT - Computed tomography

SC - subcutaneous

ARDS - Acute respiratory distress syndrome

\section{Competing interests}

The authors declare that we have not competing interests in the interpretation of data or presentation of information influenced by our personal or financial relationship with other people or organizations.

\section{Authors' contributions}

PV - Participated in the design of the study, collected data, wrote the manuscript, general supervision of the research group

PCJ - Collected data, wrote the manuscript

$\mathrm{AAB}$ - Collected data and looked for the researches made before related with the manuscript

JGM - Collected data and looked for the researches made before related with the manuscript

EBL - Revised the manuscript and analysis of data
RPP - Revised the manuscript, analysis of data and final approval of the version

All authors read and approved the final manuscript.

\section{References}

I. Bayer AS, Scheld WM: Endocarditis and intravascular infections. In: Principles and practice of infectious diseases. Volume I. 5th edition. Edited by: Mandell GL, Bennett JE, Dolin R. New York: Churchill Livingstone; 2000:857-902.

2. Andes DR, Urban AW, Acher ChW, Maki DG: Septic thrombosis of basilic, axillary, and subclavian veins caused by a peripherally inserted central venous catheter. Am J Med 1998, 105:446-450.

3. Raad I, Luna M, Khalil S, Costerton J, Lam C, Bodey G: The relationship between the thrombotic and infectious complications of central venous catheters. JAMA 1994, 27I:1014-16.

4. Verghese A, Widrich W, Arbeit R: Central venous septic thrombophlebitis - The role of medical therapy. Medicine 1985, 64:394-400.

5. Slagle DC, Gates RH: Unusual case of central vein thrombosis and sepsis. Am J Med 1986, 8 I:35I-4.

6. Kaufman J, Demas C, Stark K, Flancbaum L: Catheter-related septic central venous thrombosis - Current therapeutic options. West J Med 1986, I45:200-3.

7. Hoffman MJ, Greenfield LJ: Central venous septic thrombosis managed by superior vena cava Greenfield filter and venous thrombectomy: a case report. J Vasc Surg 1986, 4:606-I I.

8. Kniemeyer HW, Grabitz K, Buhl R, Wust HJ, Sandmann W: Surgical treatment of septic deep venous thrombosis. Surgery 1995 , I I 8:49-53.

9. Seigel EL, Jew AC, Delcore R, lliopoulos J, Thomas J: Thrombolytic therapy for catheter-related thrombosis. Am Surg 1993, 166:716-9.

10. Fraschini G, Jadeja J, Lawson M, Holmes F, Carrasco H, Wallace S: Local infusion of urokinase for the lysis of thrombosis associated with permanent central venous catheters in cancer patients. J Clin Oncol 1987, 5:672-8.

II. Rubenstein M, Creger WP: Successful streptokinase therapy for catheter-induced subclavian vein thrombosis. Arch Intern Med 1980, I 40:1370-I.

12. Ponec D, Irwin D, Haire WD, Hill PA, Li X, McCluskey ER: Recombinant tissue plasminogen activator (alteplase) for restoration of flow in occluded central venous access devices: a double-blind placebo-controlled trial - The Cardiovascular Thrombolytic to Open Occluded Lines (COOL) Efficacy Trial. J Vasc Interv Radiol 200I, I 2:95I-5.

13. Haire WD: Techniques in dosing for thrombolysis of occluded central venous catheters. Tech Vasc Interv Radiol 200I, 4: I27-30.

14. Schranz D, Haugwitz D, Zimmer B, Schumacher R: Successful lysis of a septic thrombosis of the superior vena cava using recombinant tissue-plasminogen activator. Klin Padiatr 1991, 203:363-5.

15. Lewis JA, LaFrance R, Bower RH: Treatment of an infected silicone right atrial catheter with combined fibrinolytic and antibiotic therapy: case report and review of the literature. J Parenter Enteral Nutr 1989, 13:92-8.

16. Van Rooden CJ, Tesselaar ME, Osanto S, Rosendaal FR, Huisman MV: Deep vein thrombosis associated with central venous catheters - a review. J Thromb Haemost 2005 in press.

17. Devie-Hubert I, Carlier M, Pozzo Di Borgo C: Venous thrombosis on central catheters in oncology. Rev Med Intern 1996, 17:82 I-5.

18. Van Rooden CJ, Schippers EF, Barge RM, Rosendaal FR, Guiot HF, van der Meer FJ, Meinders AE, Huisman MV: Infectious complications of central venous catheters increase the risk of catheterrelated thrombosis in hematology patients: a prospective study. J Clin Oncol 2005, 23:2655-60. 